\title{
EL VIRUS HAUSSMANN EN CHILE Y LA PANDEMIA DE TRANSFORMACIÓN URBANA
}

Ánderson Grimaldos Camacho - Luis Enrique Pizarro Villarreal*

Imagen A. Panorama de un atardecer Parisino frente a la torre Eiffel (2007). La imagen muestra la París moderna y su nuevo perfil urbano, telón de fondo que contrasta con la ciudad antigua, receptora de múltiples intervenciones que han siempre dejado en claro el deseo común de modernizar la ciudad. Fuente: http://europa.over-blog.it/

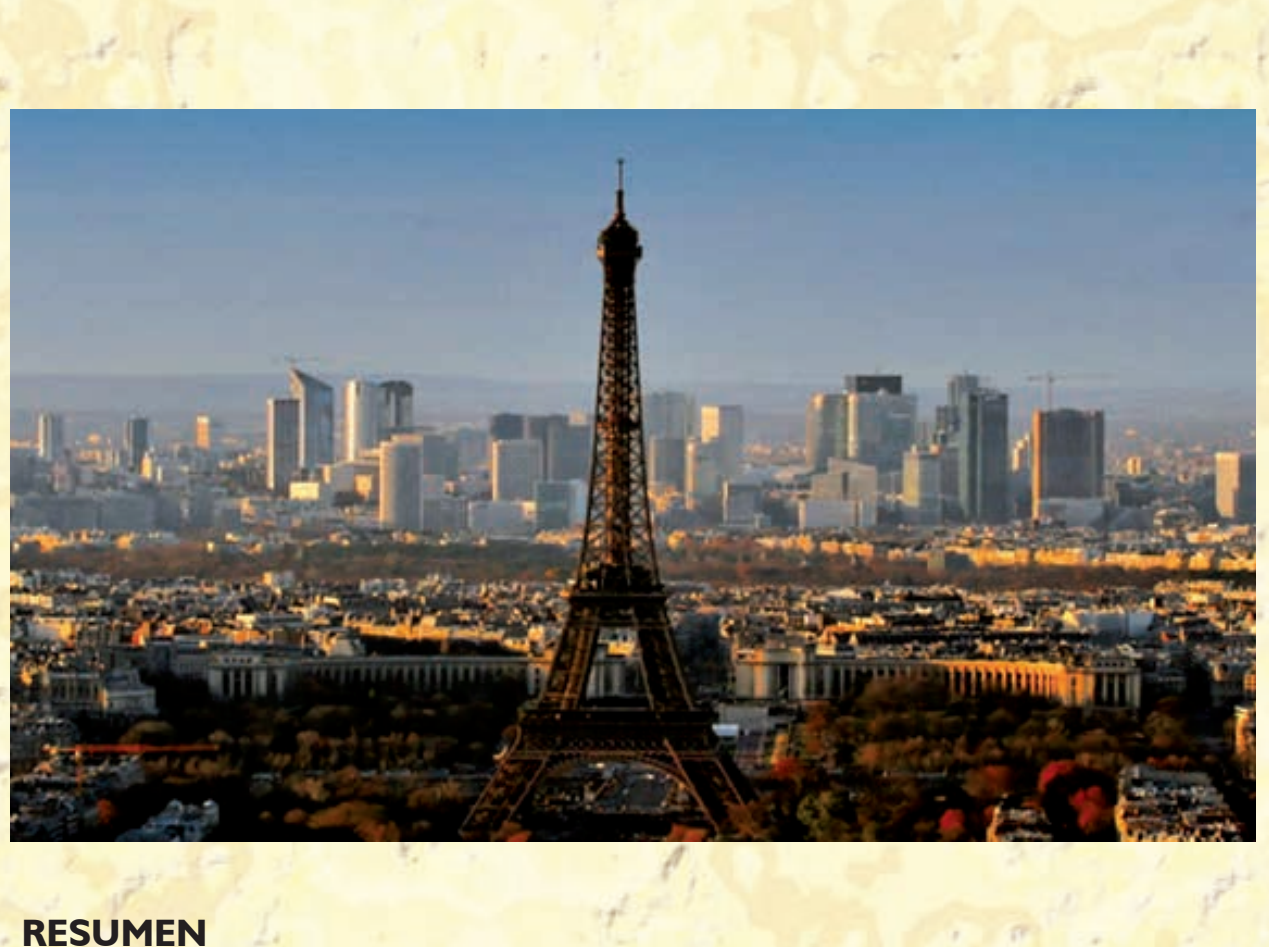

Al escudriñar en el Plan Haussmann y la intervención urbanística desarrollada en París entre los años 1853-1869, se sitúan ante nosotros las numerosas reacciones sociales, políticas y económicas que se dieron en el escenario de una ciudad sometida a drásticas intervenciones urbanísticas para transformar definitivamente su fisonomía. A partir del encargo del emperador Napoleón III, París se abandona a las manos de un hombre innovador y absolutamente decidido a intervenir radicalmente en pos de una estructura urbana más fluida, limpia y agradable para el ciudadano. Esta locomotora del urbanismo esgrimía ideales que implicaban arrasar fuertes puntos centrales en la ciudad, traducidos en todo un dramático cambio vial y la rápida construcción de nuevas viviendas, así como la implantación de servicios públicos y complementarios que darían a París una imagen diferente a la de la otrora ciudad medieval: bulevares, plazas, espacios verdes, nuevas alturas, puntos referenciales en la ciudad, y posicionamientos estratégicos de las fuerzas públicas aparecen resueltamente en medio de rebeliones y sobresaltos. Nace entonces una nueva París, la que conocemos ahora y que ha si do modelo de inspiración para artistas, filósofos, estudiosos, políticos $y$, en general, hombres preocupados por el desarrollo urbano de sus ciudades natales. Todas estas transformaciones de la Ciudad Luz contagiaron a varios chilenos, entre ellos Benjamín Vicuña Mackena, testigo presencial de esa nueva tendencia urbanística que abriría un periodo caracterizado por un interés urbano en Santiago de Chile, desde las postrimerías del siglo $X I X$ hasta la tercera década del siglo $X X$, en el cual se argumentan, se discuten y se ponen sobre la mesa varios planes, influenciados de alguna manera por Haussmann y la transformación urbana de París. Este artículo recopila en forma sucinta los principales apartes de este proceso con el fin de entender el origen de una pandemia de trasformación urbana que contagió a Santiago de Chile como a otras ciudades del planeta.

\section{PALABRAS CLAVE}

Ciudad, diagonales, habitantes, influencias, orden, París, remodelación, renovación, Santiago, trazado, urbano. 


\section{HAUSSMANN VIRUS IN CHILE AND PANDEMIC URBAN TRANSFORMATION}

Ánderson Grimaldos Camacho - Luis Enrique Pizarro Villarreal*

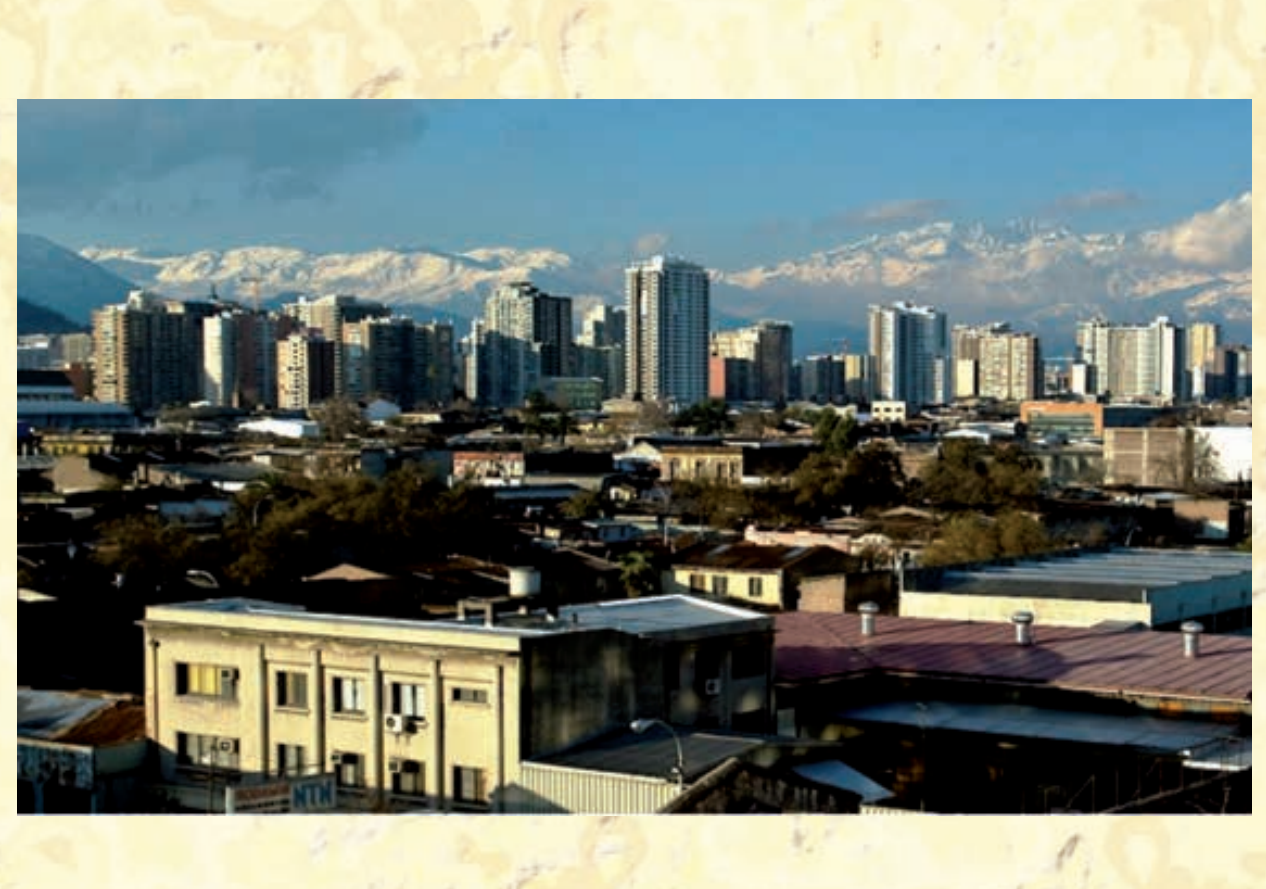

\section{ABSTRACT}

Peering into the Haussmann's Plan and the urban intervention in París, between the years 1853-1869, put us in front of many social, political and economic reactions occurred in the setting of a city that was submitted to drastic urban interventions to transform definitely their physiognomy. From the order of the Emperor Napoleon III, París was left in the hands of a man absolutely committed to innovative and radical changes towards a fluid, clean and enjoyable urban structure, more enjoyable for the citizen. This locomotive of urban planning expounded ideals that involved razing wielded strong focal points in the city, that implied a dramatic traffic shift and the rapid construction of housing and the deployment of public and complementary services that would give París a different image that the former medieval city: boulevards, squares, parks, new heights, reference points in the city, and strategic positioning for security forces appear strongly in the middle of rebellions and upheavals. A new París born then, the city that we know now and has been a model of inspiration for artists, philosophers, scholars, politicians and people in general concerned about the urban development of their hometowns. All these transformations of the City of Lights infected several Chileans, among them Benjamin Vicuña Mackenna, an eyewitness of the new urban trend that would open a period characterized by an urban interest in Santiago de Chile, from the late nineteenth century until the third decade of the twentieth century, in which were argued, discussed and put on the table several plan, somehow influenced by Haussmann's urban transformation of París. This article collects succinctly the main sections of this process in order to understand the origin of a pandemic of urban transformation that spread to Santiago de Chile and other cities on the planet.

\section{KEY WORDS}

City, diagonal, people, influences, order, París, remodeling, renovation, Santiago, design, urban.
* Estudiantes de $\mathrm{VI}$ semestre Facultad de Arquitectura, Universidad Santo Tomás, Campus de Floridablanca.

* Trabajo de investigación en aula de la cátedra de Teorías Urbano Ambientales impartida por el docente Arq. Ph.D Carlos Humberto Gómez Arciniegas

Imagen B. Panorámica de Santiago de Chile y su actual perfil urbano con muchos matices comunes al Parisino. Fuente: http://www. skyscrapercity.com/ 


\section{EL URBANISMO COMO DETERMINANTE GLOBAL DE AYER Y SIEMPRE}

La forma en que se ordena la ciudad está ampliamente determinada por muchos factores y objetivos, entre estos el de obtener mayor rentabilidad del suelo urbano, es decir, establece los sectores de mayor influencia económica, un centro más denso y una periferia más despoblada y dividida por sectores. Esto conlleva a que el desarrollo urbano más inmediato al núcleo de la ciudad sea siempre más saturado y comprometa la capacidad de su infraestructura vial y de los mismos equipamientos que a la postre serán siempre insuficientes para la demanda poblacional que crece de manera acelerada en las grandes metrópolis. De acuerdo a estos parámetros y a la falta de usos complementarios, equipamientos y sobre todo del adecuado tratamiento al espacio público se han siempre examinado planes y gestiones de renovación urbana que permitan a la ciudad encontrar una clara solución con miras al progreso y a c onvertirse en verdaderos escenarios propicios para las principales actividades humanas, en palabras de Le Corbusier: habitar, trabajar, recrearse y circular!.

Esta ha sido por mucho tiempo la preocupación de hombres de Estado, estudiosos y líderes a través de la historia. Desde Hipodamo de Mileto, 498-408 a. C. y Vitrubio, Siglo I a.C., algunos Papas, los ingleses Christopher Wren y John Nash hasta los preurbanistas de la revolución industrial, un sinnúmero de reformas urbanas se han presentado en Europa. De cualquier manera, son las transformaciones que se iniciaron después de la segunda mitad del siglo XIX las que verdaderamente marcan un nuevo comienzo del urbanismo en occidente para responder a los problemas que afrontaban en ese entonces las grades ciudades. Es así que las mejoras urbanas en París, paradigma del siglo XIX, fueron también impulsadas por los problemas higiénicos, así como por la necesidad de adaptar la trama urbana a las nuevas condiciones de la circulación y a las exigencias de funcionalización del espacio y fluidez social ${ }^{2}$. Durante ese período se cambian los focos de valorización del espacio urbano y hay que reestructurar el espacio ya edificado ${ }^{3}$. Otro común denominador en todas estas mutaciones urbanas es la fuerte connotación ideológica y política, con un alto contenido autoritario en pos de controlar el hecho urbano y la disciplina de la población. En consecuencia, nuevos órdenes aparecen para pronunciarse sobre la manera de construir, introducen una nueva estética y transforman las viviendas en mercancía que se produce en serie.

Por otro lado, las innovaciones técnicas introducidas tienen como uno de sus principales objetivos las cuestiones de higiene y las mejoras de la circulación citadina. Sin embargo todo este desarrollo dictado por la revolución industrial impone un precio: la segregación social y una nueva jerarquización del espacio con la separación de la vivienda y el trabajo $y$, lo funcional de lo social ${ }^{4}$, que encuentra fundamento en el discurso de la modernidad que preconizaba cómo el poder político derriba las viviendas pobres, los conventillos, tratando de erradicar del centro los barrios populares y de bajos ingresos: los llamados espacios nobles de la ciudad ${ }^{5}$. Esta tendencia por la reforma de los centros urbanos que, además, tiene que ver también con puras razones estéticas, se tradujo en América en una clara epidemia, inoculada por el deseo de emular a las ciudades europeas, como lo es el claro ejemplo de París.

Le Corbusier. Principios de Urbanismo (La Carta de Atenas) Barcelona, Editorial Planeta, 1993

2 Una serie de investigaciones bien conocidas, han demostrado que la realidad social ha devenido fluida, fragmentaria, móvil y flexible. Al respecto consúltese CASTELLS, Manuel. La cuestión Urbana. Madrid, Siglo XXI, 1974

3 PETTI PINHEIRO, Elisa. Europa, Francia y Bahia. La difusión de los modelos europeos. Escuela técnica Superior de Arquitectura, Universidad Politécnica de Cataluña, Barcelona, 2000

4 lbídem.

5 Ibídem. 


\section{EL PLANTEAMIENTO DEL BARÓN GEORGE HAUSSMANN Y EL CONTAGIO DE VICUÑA MACKENNA}

Sin duda la transformación de París, realizada por Georges Eugène Haussmann (París 1809-189I) más conocido con el nombre de Barón Haussmann, terminó convirtiéndose en un modelo urbanístico, desde fines del siglo $\mathrm{XIX}$ hasta la tercera década del siglo $\mathrm{XX}$ (Ver Imagen I) Para Haussmann:

"la ciudad era el gran escenario en el que una sociedad rica y desprejuiciada realiza el ritual de su acontecer diario, en el marco político-social del Segundo Imperio. Atrás quedan los tiempos de las viejas monarquías absolutas, barridas por la Revolución y el Imperio Napoleónico, el Primer Imperio, caído bajo el peso de su propia arrogancia".

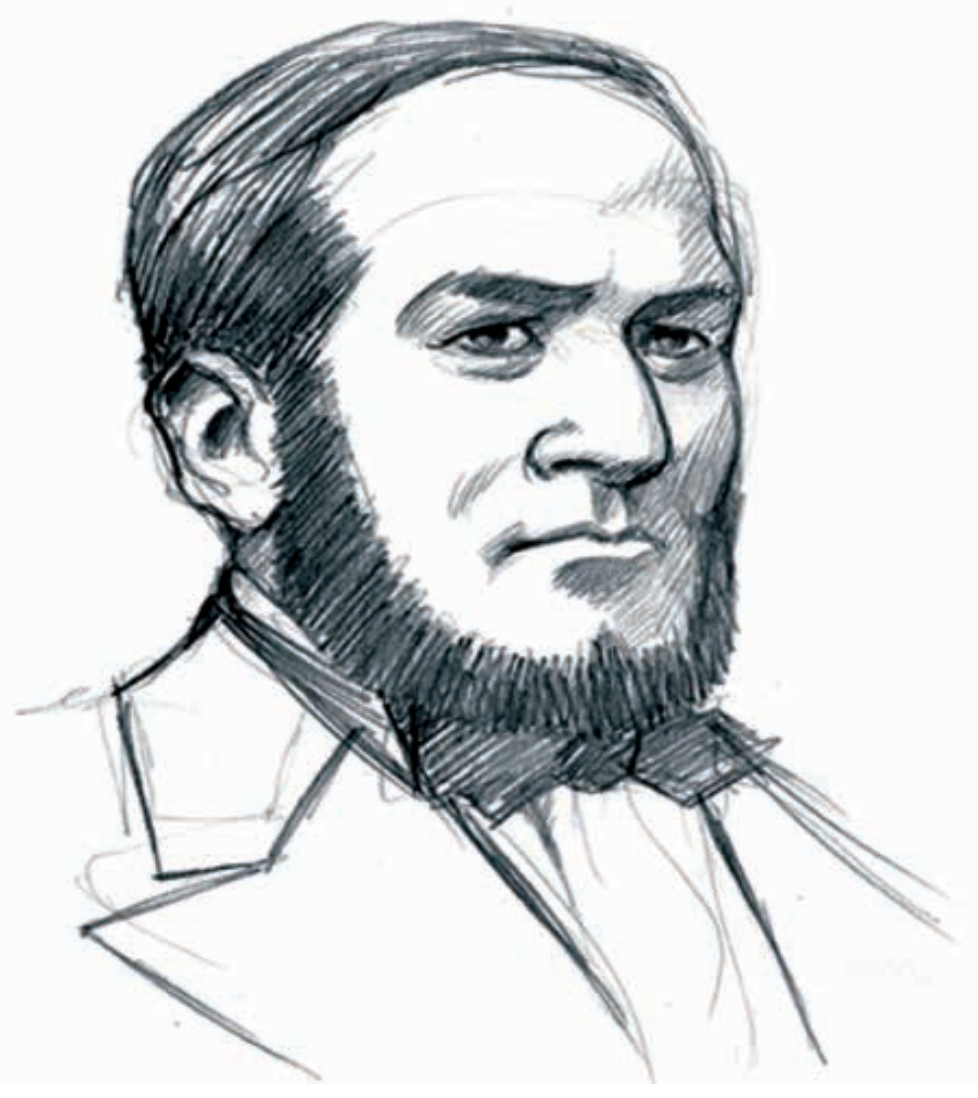

Imagen I. El Barón Haussmann Fuente: http://www.paturaud.com

Este nuevo orden político allanó el camino para el Barón Haussmann, francés nacido en el seno de una familia protestante, que consolidó desde joven una cercanía con la política y le permitió tener un rol protagónico en el plan de renovación urbana de una París que, en la época conservaba mucho de su carácter medieval (Ver Imagen 2). Su preocupación principal por la ciudad fue la calidad de la vida urbana por lo que pensaba en un programa de mejoramiento social y cultural. Este plan abarcaba, en líneas generales, ciertos aspectos de mejoramiento físico, entre los que se cuentan:

6 MARTÍNEZ LEMOINE, René. Santiago. Los Planos de transformación I894-1929. En: Revista Electrónica DU\&P. Diseño Urbano y Paisaje, Volumen IV No. 10, Centro de Estudios Arquitectónicos, Urbanísticos y del Paisaje, Universidad Central de Chile, Santiago, 200I 
- Apertura de calles

- Pavimentación

- Canalizaciones

- Dotación de agua potable

- Se agregaban medidas de saneamiento (clínicas)

- Habitaciones obreras

- Demolición de viviendas

- Construcción de escuelas

- Organización de la policía

- División administrativa

- Zonas verdes en todas las vías

Este mejoramiento hizo que se expulsara del centro de la ciudad a las clases modestas, para que de allí se pudieran construir viviendas burguesas, situación que genera que el hecho urbano se sectorice y se empiece a formar una ciudad divida en clases sociales ${ }^{7}$. En síntesis, la labor de Haussmann fue abrir la ciudad hacia una nueva perspectiva, lograda a través del sacrificio de muchas zonas que tenían un trazado irregular y que implicó abrir amplias avenidas que la cruzaban, valiéndose de una estrategia que consistía en conectar y resaltar los edificios más significativos con paseos urbanos y grandes bulevares para atraer el turismo, dar un nuevo aire a la ciudad y, al mismo tiempo, prepararla para el reto del caos y las congestiones que muchas ciudades afrontan hoy. Todas estas transformaciones de París contagiaron a Vicuña Mackenna, testigo presencial de la nueva tendencia urbanística, quien como corresponsal de "El Mercurio" en París, escribió:

"París está profundamente transformada. La ciudad no es ni la sombra de la que yo conocí hace quince años"8

Más adelante esta visita a París la recordaría como intendente de Santiago en I872:

“(...) a que yo estaba recién llegando de Europa, esto es, empapado de todas las ideas y prácticas de la cultura moderna en relación a la edilidad de las ciudades y el gobierno doméstico de los pueblos."

Lo anterior sirve de preámbulo para hablar de Vicuña Mackenna como precursor de la transformación de Santiago y del antecedente inmediato de un periodo que se prolonga por lo menos hasta 1930, cuando el pensamiento urbanístico se identificaba con la idea de transformación, derivada del ejemplo Parisino que continuaría con la influencia de políticos y urbanistas protagonistas aliados de las transformaciones urbanas de otras ciudades de América Latina.

BENÉVOLO, Leonardo. Historia de la Ciudad. Bari, 1976

DONOSO, Ricardo. Don Benjamín Vicuña Mackenna. Santiago, Imprenta Universitaria, 1925

ORREGO VICUÑA, Eugenio. Vicuña Mackenna, vida y trabajos. Editorial Zig-Zaag, 195I 


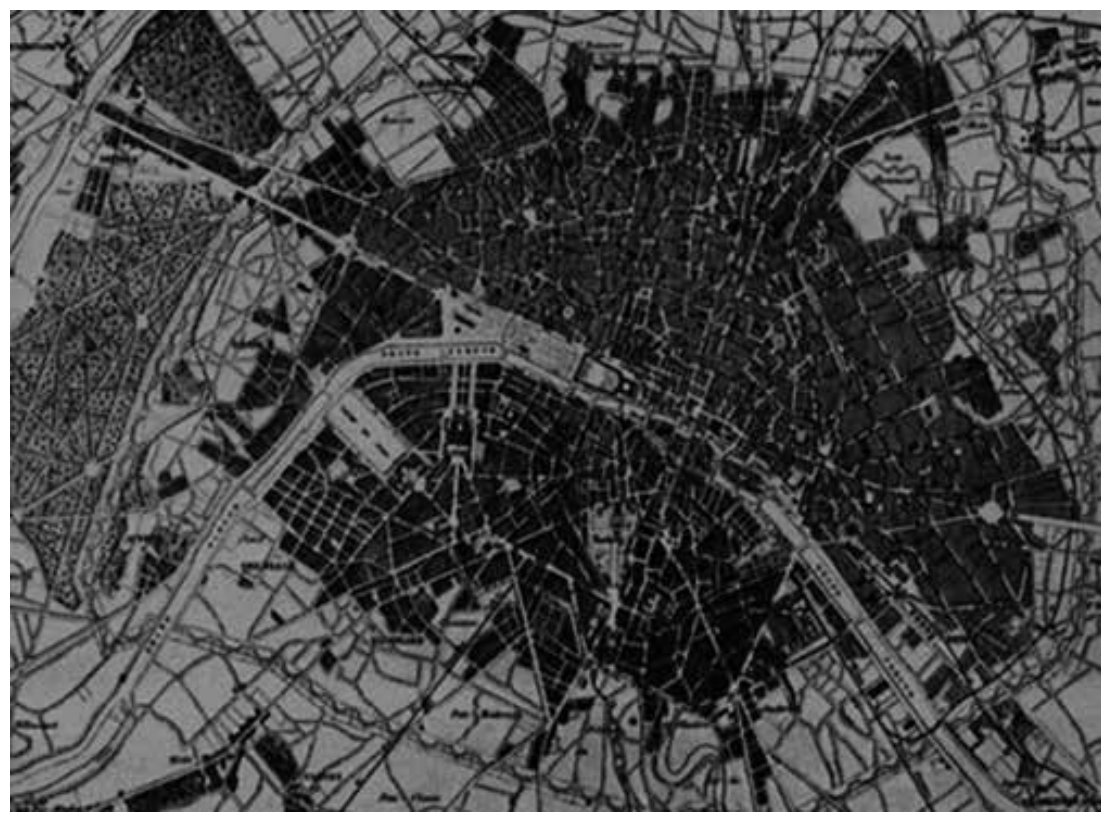

Imagen 2. Planta de París en 1853 anterior a los trabajos de Haussmann. Fuente: http://www.upf.edu

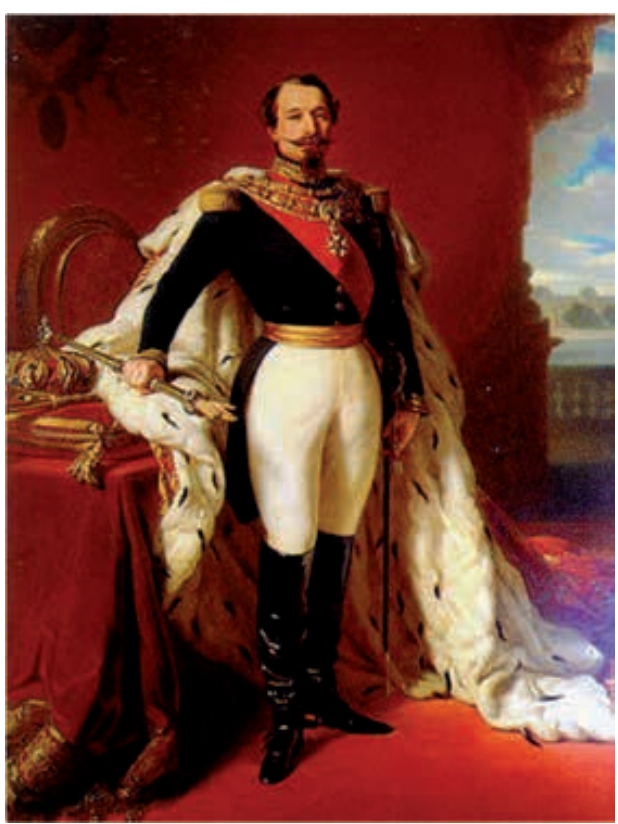

Imagen 3. Carlos Luis Napoleón Bonaparte (París, 1808 Chislehurst, Kent, Inglaterra, 1873). Fuente: www.omnigrafia.com

\section{LOS ENCARGADOS DE UN AMBICIOSO PLAN DE RENOVACIÓN}

Para consolidar un plan de renovación urbana se debe contar con el consentimiento del poder político. Si hablamos de París, este proceso pudo ver una luz con los extendidos poderes del emperador Napoleón III, Presidente de la República y emperador de Francia (Ver Imagen 3), sobrino del primer Napoleón y quizá hijo natural suyo. En su juventud tuvo una trayectoria como conspirador liberal, al participar en los movimientos revolucionarios italianos de I83I.

Refiriéndonos a su relación con el barón Haussmann, recibió el encargo de Napoleón III de llevar a cabo un programa de reformas en París, seguramente movido porque Napoleón "el pequeño", necesitaba justificarse y emular las antiguas casas reinantes europeas que ya miraban con atención el fenómeno urbanístico derivado de las Exposiciones Universales, el City Beautiful Mouvement, traducido en los tratados de la época como la preocupación que se expresa en el embellecimiento de la ciudad como finalidad última y única sin consideraciones de tipo funcional, económico o social ${ }^{10}$. En el caso de Santiago de Chile fue Benjamín Vicuña Mackena subalterno del entonces presidente Federico Irrazurris Zanartu (Santiago I 825- I 877) quien lo nombró intendente de Santiago, dándole así la autorización para poner la primera piedra de la transformación de Santiago. De cualquier manera, estos aspectos se contemplarán en el desarrollo de este artículo, no después de haber abordado el caso de la transformación de París.

10 Oficialmente se registra como primera Exposición universal, la de Londres en I85 I, famosa por el Cristal Palace de Joseph Paxton, trasladado del lugar original y después destruido por un incendio. Los orígenes del urbanismo moderno: Leonardo Benévolo. 


\section{EL PLAN DE REMODELACIÓN DEL CENTRO DE PARÍS (1853- 1869) COMO PARADIGMA DE LAS PRIMERAS INTERVENCIONES EN SANTIAGO DE CHILE (1872-1875)}

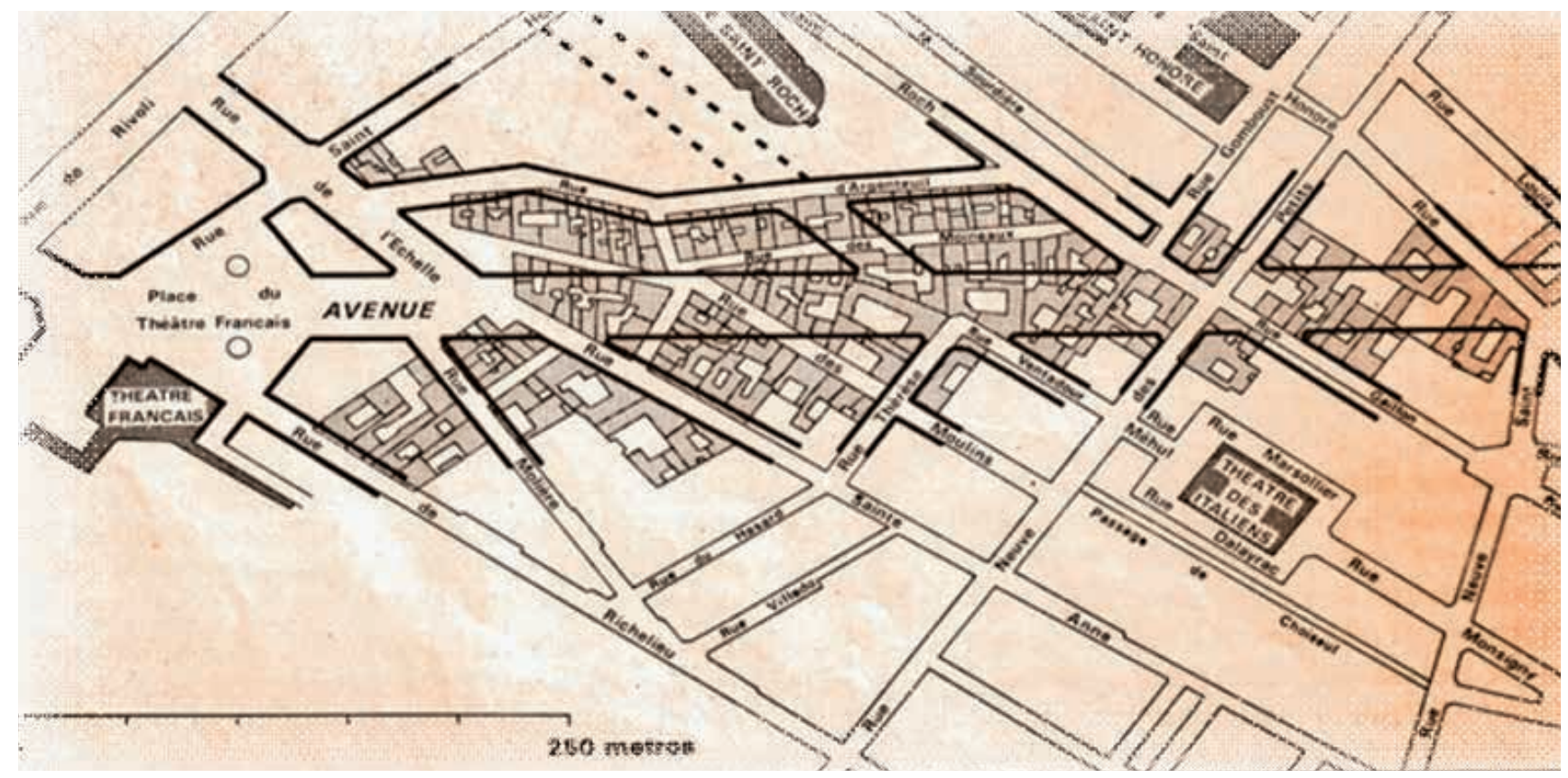

Imagen 4. Avenida de la Ópera. La imagen indica las nuevas fachadas y los terrenos afectados en la Avenida de la Ópera, sector interesado por el Plan de Haussmann. Para implantar esta gran vía el Estado, como primera medida, expropia a los dueños de los terrenos concernidos por los nuevos planos de remodelación, luego se llevan a cabo las respectivas demoliciones de edificios para la construcción de nuevos ejes con todos sus equipos: agua, gas, desagüe, alumbrado y demás. El resultado sobre el espacio privado: la destrucción de 20.000 casas antiguas para construir más de 40.000 entre 1.852 y 1.870 ( CARS, J.; PINON, P. París Hausmann. París, 1991). Fuente: https://www.courses.psu.edu/
Concretamente, el desarrollo del Plan se elabora mediante una serie de objetivos propuestos por Haussmann quien opta por dar solución a un sistema de higiene pública, ordenamiento de los servicios y fines defensivos, entre otros. Esta empresa no sólo obtuvo apoyo en el poder político del entonces gobernante, Napoleón III, sino que contó también con el alto nivel de los técnicos, quienes comenzaban a adueñarse de nuevos sistemas de construcción e industrialización, la Ley de expropiación de 1840 (Ver Imagen 4) y la Ley sanitaria de 1850. El resultado se refleja, por lo tanto, en el desarrollo de un programa urbanístico coherente en un periodo de tiempo bastante corto. Desde este momento, los nuevos trazados sobre la malla urbana parisina se adoptan como modelo reconocido por muchas de lo que son hoy las grandes ciudades del mundo, desde mediados del siglo XIX en adelante"l.

Al hacer referencia específica a las intervenciones urbanas de Haussmann, después de la vía libre de Napoleón III, procedió entonces a diseñar el Bois de Boulogne (Bosque de Boloña) e hizo amplias mejoras en parques menores. Árboles de los jardines del Palacio de Luxemburgo fueron talados para permitir la formación de nuevas calles y el Bulevar de Sebastopol, cuya mitad meridional es actualmente el Bulevar Saint Michel, trazado a través de un distrito populoso. Al mismo tiempo, tuvieron lugar cambios drásticos para hacer anchos bulevares de lo que hasta entonces eran calles estrechas ${ }^{12}$.

II Transformación de París durante el Segundo Imperio. http://www.esacademic.com

12 Ibídem. 


\section{LA NUEVA CARA DE PARÍS Y LOS GRANDES TRABAJOS DE HAUSSMANN DE I853-1869}

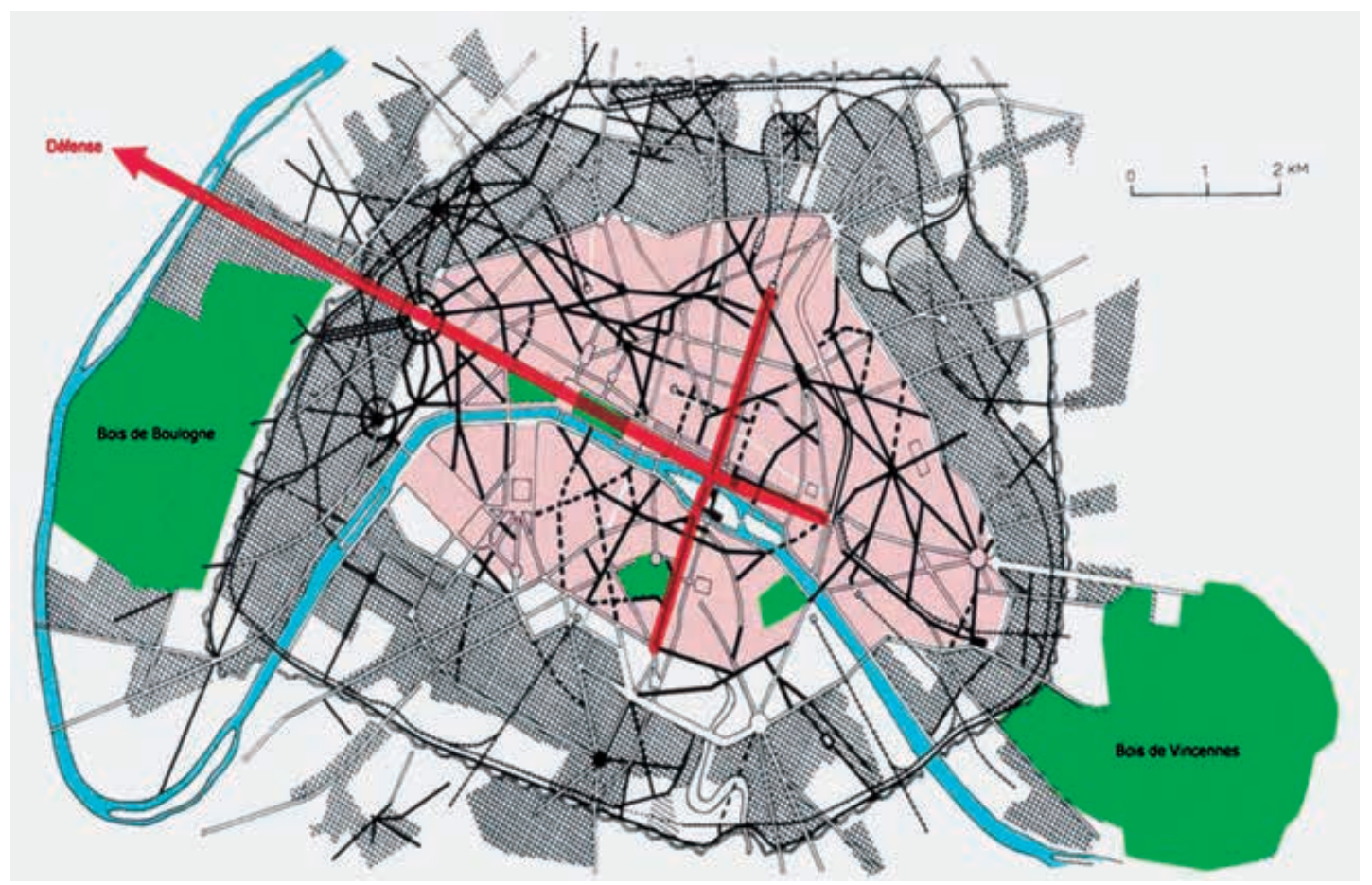

En la gráfica se aprecia el trabajo de Haussmann que se generó a gran escala. Se puede apreciar en color rosa el área del París pre-Haussmann con I 2 arrondissements y la trama vial que él propone, en líneas negras fuertes. Aparecen además nuevos barrios (representados con el achurado) que dan a su vez lugar a dos grandes parques periféricos (Bois de Bologne e Bois de Vincennes) como tentativa de darle a la ciudad escenarios verdes que además de su valor ambiental contribuirán a darle un toque característico a la ciudad. Es además evidente el interés por mantener y crear espacios públicos y de recreación al aire libre, no sólo en la periferia de la ciudad sino en toda su distribución interna, razón que explica la aparición con el tiempo de pequeños parques dentro de la ciudad. Finalmente, en rojo se aprecian los dos grandes ejes de parís que fueron ampliados drásticamente para dar importancia a una conexión lineal visual y monumental entre el Lovre y la Place de Gaulle (hoy Place de l’Etoile), a través de los ya famosos Campos Elíseos.

Las nuevas calles trazadas sobre la trama urbana cortan en varios sentidos el tejido medieval que distribuía los barrios parisinos. Además la remodelación urbana de París contó con la implantación de nuevos servicios de infraestructura básica, la instalación del alumbrado a gas, nuevas redes de transporte público y una organización definida de escenarios educativos, hospitalarios, prisiones y sobre todo amplios jardines. Por otra parte, Napoleón IIl y Haussmann coinciden en devolverle también a la ciudad la importancia a los grandes monumentos como teatros y obras representativas de París, a lo que el Barón responde con la ampliación de las avenidas centrales con una anchura de 20 y hasta 30 metros, y una fina importancia a los bulevares (Ver Imágenes 6, 7 y 8)
Imagen 5. Los grandes trabajos de Haussmann. Fuente: www.cittasostenibili.i y Benévolo Leonardo, La Historia de la Ciudad, Op. Cit. 
Imagen 6. Boulevard Henri-IV La apertura del Boulevard Henri-IV, una idea genial de Haussmann, que entendía la hermosa perspectiva que podría establecerse entre la columna de la Bastilla y la cúpula del Panteón tuvo que superar el escepticismo de Napoleón III, que no apreciaba la línea recta. Fuente de texto: Charles Marville / Editorial Mecenas et Gilles Leimdorfer para Le Figaro Magazine. Fuente de imagen: www.lefigaro.fr


Imagen 7. Calle Soufflot. La calle Soufflot en 1877 y en la actualidada. La perspectiva no existía a principios del siglo XIX y la calle que lleva el nombre del arquitecto del Panteón terminaba en un callejón sin salida a la altura la calle Saint-Jacques. Su alargamiento hacia Saint-Michel se inició durante el Segundo Imperio. Fuente: Charles Marville / Editorial Mecenas et Gilles Leimdorfer para Le Figaro Magazine. Fuente: www.lefigaro.fr 


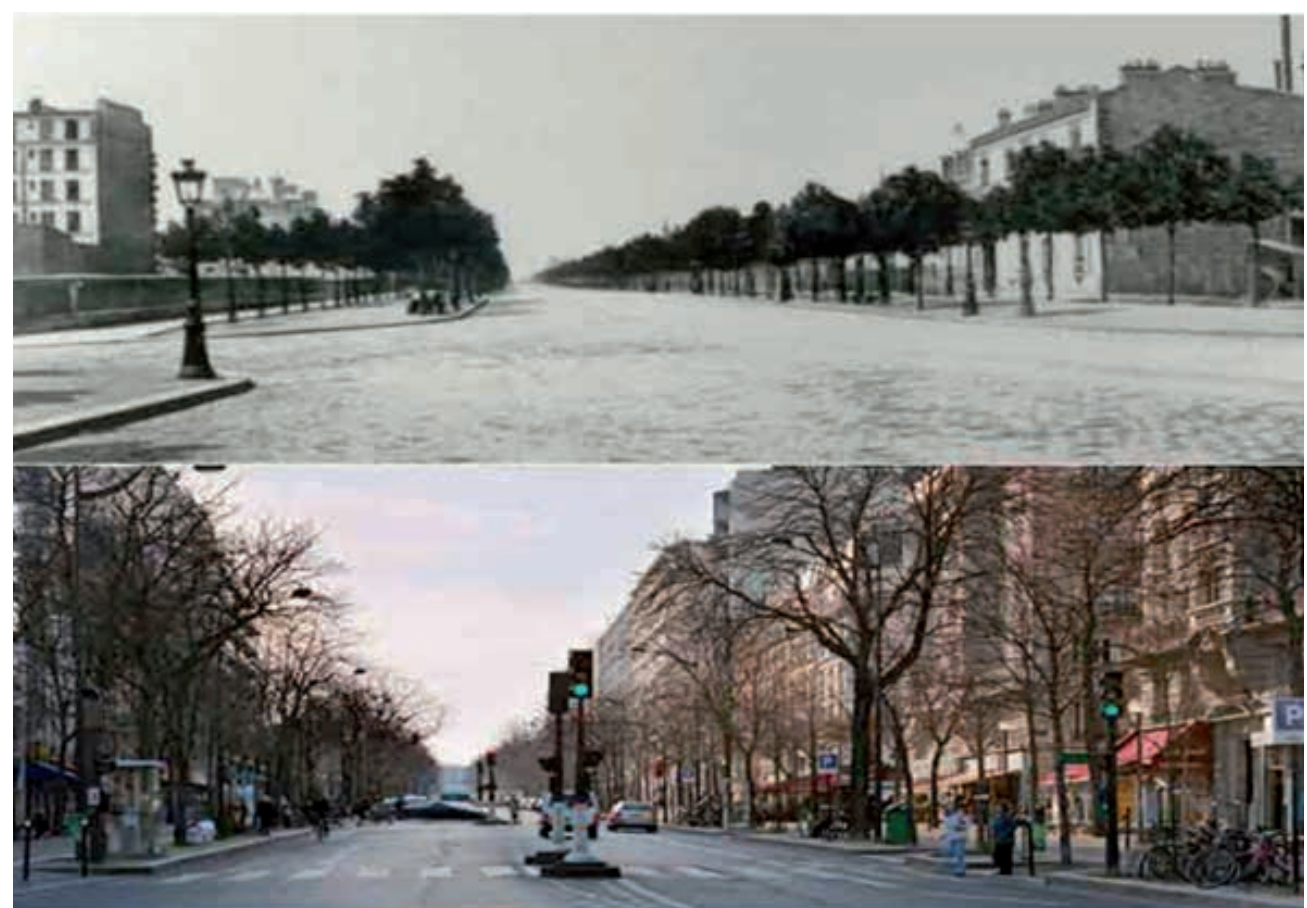

La conclusión de esta gran empresa fue una completa obra de transformación de París, ideada por Haussmann y especialmente aplaudida por las clases enriquecidas, pero en gran parte criticada por el pueblo parisino que sintió que la obra de Haussmann destruía sus raíces y conexiones sociales, a causa del desplazamiento de las masas obreras del centro de la ciudad a los barrios de la periferia (Ver Imagen 8). En otras palabras, un injusto pago para la clase que más sufrió las precarias condiciones de vida del antiguo París medieval y que la exilió a los suburbios por la haussmannización que arrasó los barrios bajos y los sustituyó por apartamentos para la burguesía. Esta intervención fue tan drástica que los límites urbanos del setecientos desaparecieron y una serie de municipios periféricos quedaron anexos a los de París. A Pesar de ello, París resurge para dar respuesta a las exigencias impuestas por la revolución industrial y para ganarse un puesto como paradigma urbano a nivel mundial. El chileno Benjamín Vicuña fue testigo presencial de este cambio y no dudó en asimilarlo y, sobre todo, adaptarlo para su amada Santiago de Chile.

\section{HACIA LA PRIMERA RENOVACIÓN DE VICUÑA EN DE SANTIAGO DE CHILE}

Las intervenciones urbanas en Santiago de Chile no solamente responden a las corrientes vanguardistas de sus políticos o planificadores. Esta ciudad ha sufrido gran cantidad de terremotos a lo largo de la historia que han esculpido una y otra vez su fisonomía. La ciudad, como sus homólogas latinoamericanas, ha tenido que afrontar grandes problemas como situaciones anómalas de orden social que la llevaron a recibir en tiempos de la colonia el nombre de "la ciudad de albergues de holgazanes y baldíos", donde "el vicio a sus anchuras mora", según lo dicho en 1596 por el poeta Pedro de Oña. Más adelante aparecen problemas por el crecimiento urbano sin un orden, reflejado en la sectorización de la ciudad, hacinamiento, enfermedades por el mal manejo de las aguas potables $y$
Imagen 8. Boulevard Aragò El Boulevard Aragò fotografiado por Marville en 1867. Tres años después de su apertura. los predios sobre esta arteria no se habían habitado a pesar de las grandes subvenciones lanzadas por el Estado. En la mayoría de los barrios elegantes, la especulación latía fuertemente. (Charles Marville / Editorial Mecenas et Gilles Leimdorfer para Le Figaro Magazine). Fuente: www.lefigaro.fr 
Imagen 9. Plano de Chile. Viejas calles empedradas y casas coloniales construidas de adobe, techos de doble caída y tejas formaban el paisaje urbano del Santiago de Chile antes de su modernización, iniciada por Vicuña. Este plano, dibujado entre 1834 y 1836 proporciona una idea del estado de Santiago antes del impulso de revolución industrial y del pensamiento de una trasformación urbana general, probablemente el primero en la historia de esta ciudad y originado en la mente de Vicuña Mackenna Fuente: http:// www.macalester.edu/ residuales $^{13}$. Tras los daños causados por la naturaleza, especialmente por los terremotos de 1822 y $1855^{14}$, se pensó en la alternativa de trasladar la capital chilena a otra parte del país más segura pero, a pesar de esta intención, promovida por algunos ciudadanos y políticos, la maltrecha ciudad siguió su andar y conforme pasaron los años, con un perfil urbano caracterizado por edificaciones de un solo piso en la zona residencial e iglesias con grandes fachadas que denotaban el poder del la iglesia católica y terminaban como un complemento de la ciudad en ese entonces (Ver Imagen 9). ${ }^{15}$ Es así que Chile, poco a poco, desechaba la idea de trasladar su capital a otro sector del país, tal vez porque, los mismos capitalinos se encargaron de que esto no ocurriera al mostrar síntomas de unión y fuerza, para así poner en evidencia su misma capacidad de progreso y temple hacia un problema al que siempre tendrán que hacer frente: la fuerza de la naturaleza.

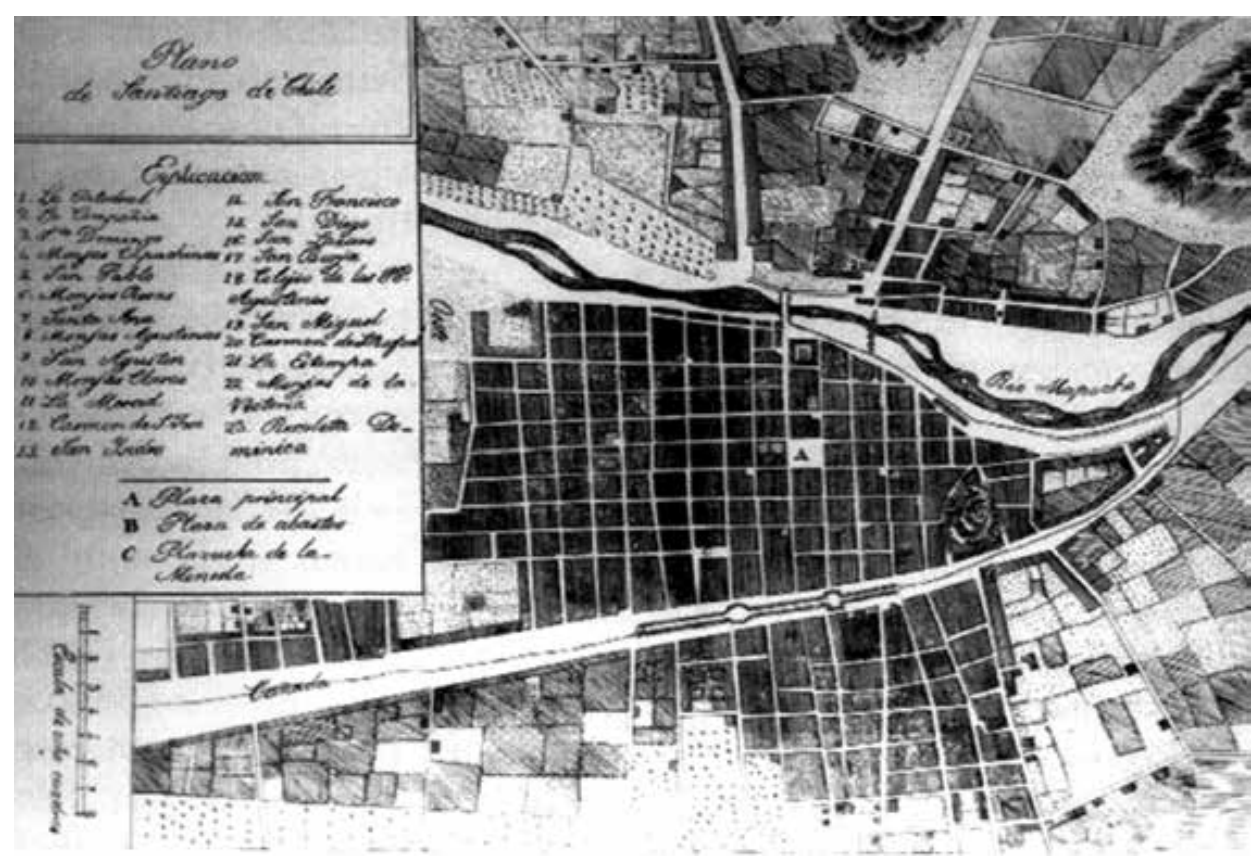

En consecuencia, los chilenos sólo pensaron en agrandar su capital a través de un crecimiento por extensión, al yuxtaponer un sector antiguo con uno nuevo pero sin un orden entre ellos, sin una planificación que permitiera evitar problemas futuros, como la expansión urbana sin control, el mal manejo de las aguas, la aparición de industrias de impacto ambiental y la sectorización de las clases, entre otros factores, dinámicas que con el tiempo maltratarían y deteriorarían la ciudad.

Este preámbulo es simplemente un diagnóstico de lo que habría de ser una propuesta de renovación urbana: la ciudad necesitaba un estudio inmediato para afrontar los problemas ya mencionados pues crecía sin control y hasta el momento no había aparecido ninguna persona que asentara con mano dura una solución. Santiago tuvo que esperar entonces hasta 1872 cuando apareció en el escenario urbano de Santiago, Benjamín Vicuña Mackenna (Santiago de Chile, I83I - Santa Rosa de Colmo, I886'6.

3 Pedro de Oña (Angol, I570 - Lima 1643) fue un teólogo, poeta y funcionario colonial español, nacido en Chile. Su principal obra es Arauco Domado. Fuente: http://www.municipalidaddesantiago.cl/comuna/ comuna_450-adelante.php

14 DE RAMÓN, Armando. Santiago de Chile (I54I-199I): Historia de una sociedad urbana. Santiago, Chile: Editorial Sudamericana, 2000

15 La primera iglesia franciscana, fue levantada en 1599 por dos frailes llegados de Santiago del Estero. Ibídem.

16 Benjamín Vicuña I83 I-1886 fue un destacado historiador, escritor, político, modernizador y viajero impenitente, chileno. realizó sus estudios en el Instituto Nacional y la Universidad de Chile, graduándose de abogado en I 857. 


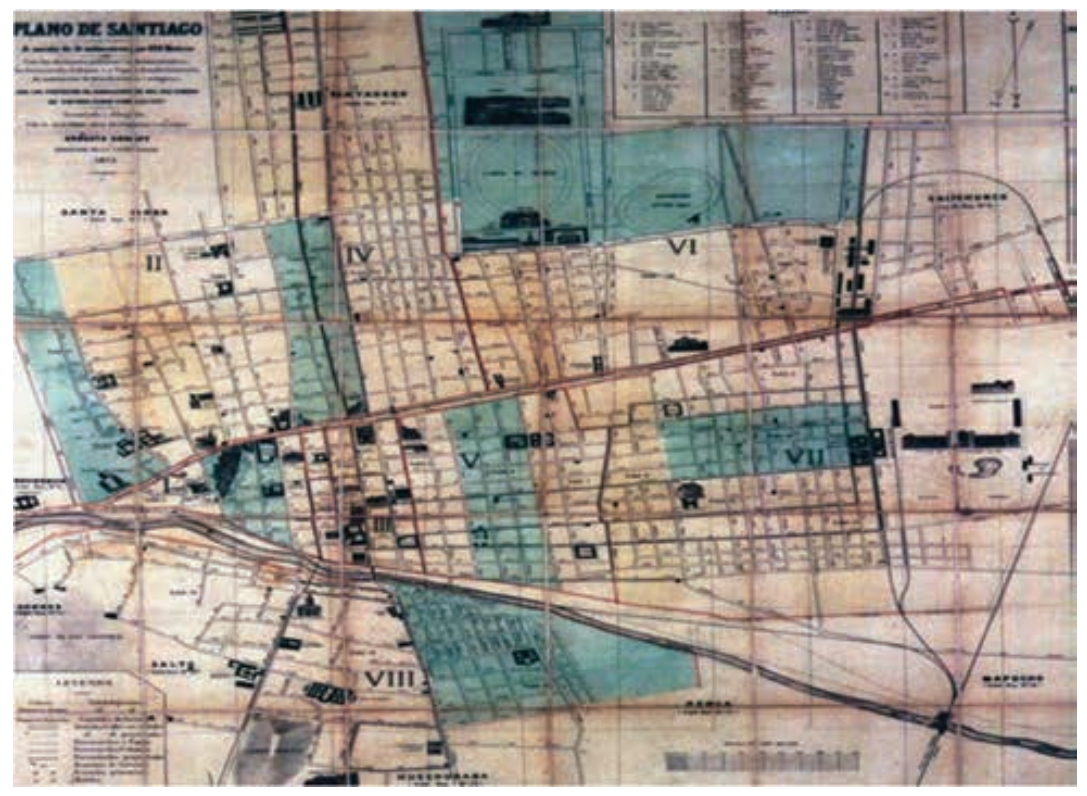

Imagen II. Plano de Santiago de Chile por Ernesto Ansart 1875. Fuente: http://www.ucentral.cl/dup/pdf/10_ santiago_planos.pdf

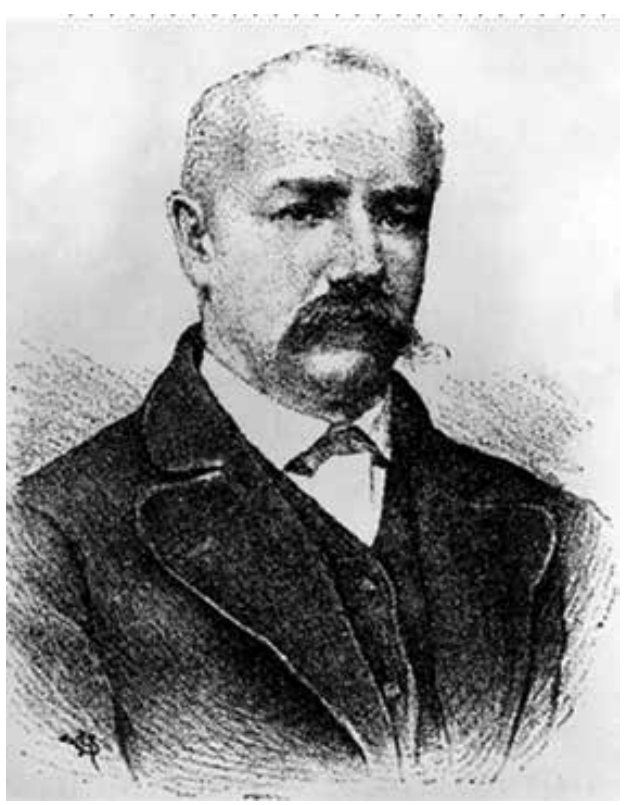

Imagen 10. Benjamín Vicuña Mackenna. Fuente: http:// www.educarchile.cll

\section{PLAN URBANO DE SANTIAGO DE CHILE}

La iniciación de la remodelación de Santiago (1872-1875) se dio gracias a maniobras involuntarias del presidente Federico Irrazurris Zanartu quien nombró intendente de Santiago a Benjamín Vicuña Mackenna. Es así que Vicuña acepta el cargo e inmediatamente lo utiliza para proponer un proyecto de transformación de la ciudad, pues como político e historiador ya había entrevisto la necesidad de llevar a cabo una remodelación urbana de la vetusta Santiago. Para ello, debía contarse con un plano científico de la ciudad, tarea que correspondió realizar al ingeniero Ernesto Ansart bajo la dirección del propio intendente. El plano de Ansart fue editado en Francia en 1875 y constituye hoy una rareza cartográfica ${ }^{17}$.

Estudios demuestran que la preocupación del intendente

"se dirigió, en primer lugar a la calidad de la vida urbana. El Plan de trabajo, presentado al Consejo Municipal abarcaba no sólo los aspectos formales y estéticos, tales como la formación de plazas y monumentos, sino que en esencia se pensaba en un programa de mejoramiento social y cultural de la ciudad. A los aspectos físicos, tales como pavimentación, canalizaciones, dotación de agua potable y apertura de calles, se agregaban medidas de saneamiento y construcción de habitaciones obreras, demolición de viviendas insalubres, construcción de escuelas y casas de recreación popular". A ello se sumaron una serie de medidas relativas al orden y división administrativa, fijación de límites urbanos, organización de la policía, entre otras"18.

A pesar de esta plausible intención, Vicuña durante su paso por la intendencia (I8721875) realizó costosos y desmedidos cambios para embellecer la ciudad, que en ningún

17 MARTíNEZ LEMOINE, René. Sa tiago. Los Planos de transformación I894-1929

18 Íbidem 
Imagen 12. Cerro de Santa Lucía. El Cerro de Santa Lucía fue uno de los proyectos liderados por Vicuña, dotándolo de estanques de acumulación de aguas, fuentes de agua, terrazas preparadas para vegetación, caminos para carruajes, jardines, una ermita, miradores, edificio destinado para museo en el actual Castillo Hidalgo y construcciones propias de un parque urbano inspirado en el paisajismo francés que predominaba en la planificación de la época. Fuente: www.eap.ucop.edu.com

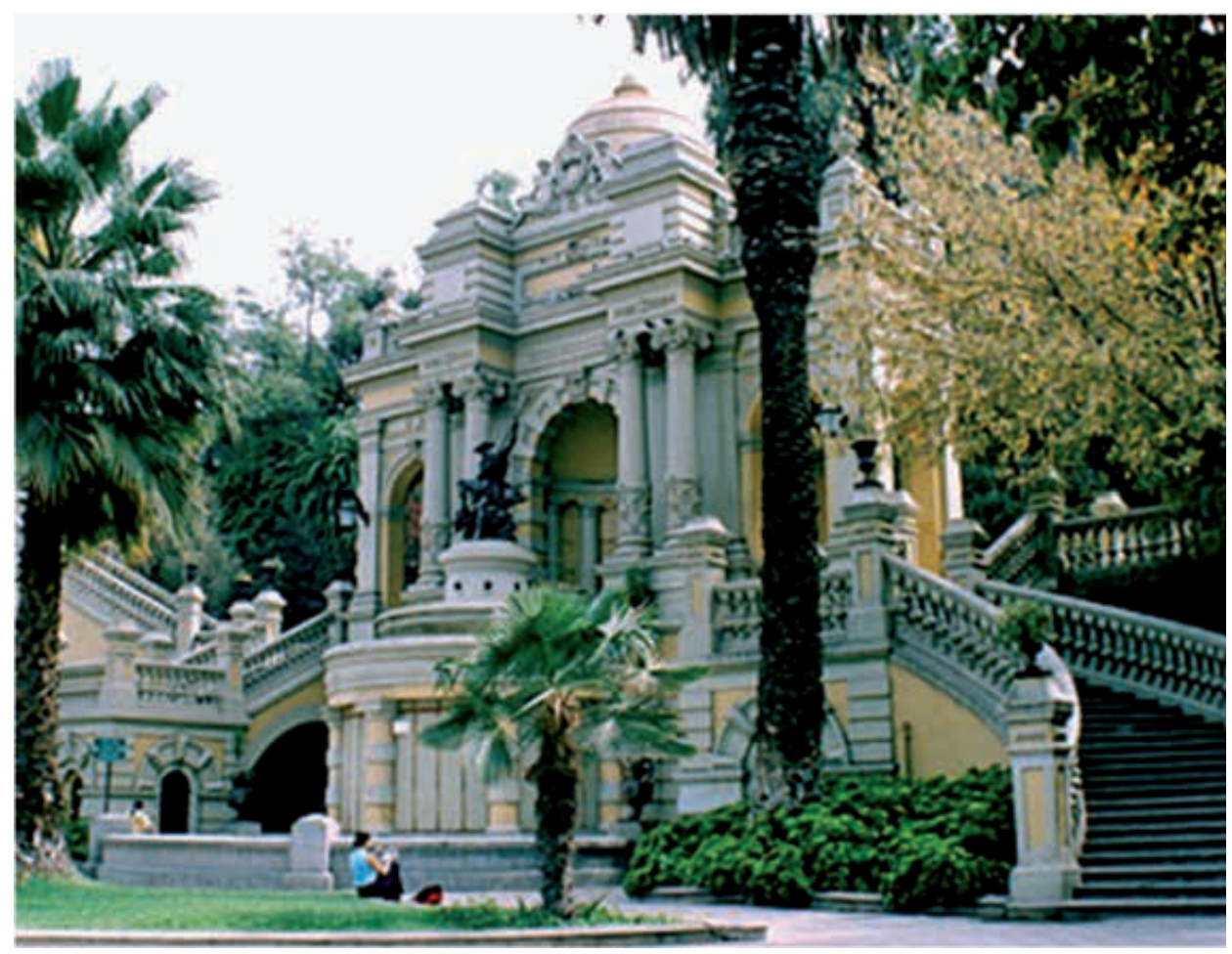

momento escondían su afán por adoptar las tendencias Europeas. Entre estos se destaca la remodelación del olvidado cerro de Santa Lucía (valioso por su contenido paisajístico) y el célebre Camino de Cintura (Ver Imagen 12) Para descargar a los barrios centrales del exceso de tráfico y crear en el borde urbano una red de paseos interconectados ${ }^{19}$.

Se puede decir, en otras palabras, que Vicuña buscaba modernizar el modelo de vida urbana y prevalecer el orden, la belleza y la cultura dentro de la convivencia espacial y social de sus habitantes, ya que además de la estructura urbana se preocupó por generar ciertas conductas y hábitos de sus habitantes al promover así la erradicación de ciertos vicios como la mendicidad, la prostitución y la pobreza. Sin que todo esto fuese poco, Vicuña Mackenna propuso y construyó otros adelantos de esta época como la instalación de los primeros teléfonos en 1880 y el alumbrado eléctrico en la Plaza de Armas y algunos edificios del Centro en 1883.

\section{LA ESCUELA EUROPEA Y SU INFLUENCIA DURANTE Y DESPUÉS DE VICUÑA}

El intendente estuvo tan involucrado con su ciudad, ya fuera desde la parte política o como historiador, que siempre se preocupó por cambiar lo que se inició mal para lograr que la capital chilena se destacara a nivel de Latinoamérica o mejor aún a nivel mundial. En uno de los viajes que tuvo que hacer a Europa, por cuestiones personales al estar involucrado con los liberales, pudo estudiar a la perfección lo que en Europa fue un acontecimiento a nivel mundial: el planteamiento urbanístico planteado por el Barón Haussmann. De hecho, estos ideales fueron adoptados por grandes arquitectos y urbanistas de talla mundial que llevaron a sus países de origen los planteamientos de Haussmann para que ciudades como Buenos Aires, Sao Paulo y Lima, entre otras, sufrieran un cambio rotundo que les

19 Íbidem 
proporcionara un mejoramiento notable en muchos aspectos, desde la estructura física hasta el fortalecimiento social y cultural de la ciudad.

Esto explica la visión de Benjamín Vicuña como una gran oportunidad de cambiar su ciudad natal para enfrentar retos ancestrales y para poner sin duda alguna a Santiago de Chile junto a la categoría de las otras ciudades suramericanas importantes, que ya han sido nombradas en las líneas anteriores. Este objetivo se pudo cristalizar gracias a su influencia en la política ya que como intendente, Vicuña no tuvo problemas para aplicar estos grandes principios a su ciudad. Obtuvo además el visto bueno del entonces Presidente y de las personas que estaban por encima de su poder para finalmente ver que la ciudad "quedaba en sus manos" y con vía libre para darle un nuevo rumbo y encontrar nuevas soluciones a los problemas que se afrontaban en aquel entonces.

Un hecho notable de la gestión y realización de Vicuña Mackenna es el alto nivel de racionalidad urbana. Nada hay de fantasioso en la escena urbana creada por el gran intendente. Cuando las naciones del mundo, de acuerdo con el ejemplo de París, se empeñaron en la apertura de diagonales, urbi et orbi, en toda la obra escrita por Vicuña Mackenna no existe referencia alguna de aperturas diagonales, ni proposiciones al respecto. Esto es tanto más notable cuanto los seguidores de Vicuña Mackenna durante el medio siglo siguiente, concentraron sus proposiciones en la más indiscriminada apertura de diagonales. En todo caso, debe quedar en claro que sin Vicuña Mackenna y sin su plan de transformación no podría explicarse ni entenderse nada de lo que sucedería en los próximos 50 años, desde su mandato como intendente hasta 1930. De hecho, después de la idea inicial de Vicuña se plantearon siete proyectos de transformación, de los cuales los más relevantes se mencionan a continuación:

Primer proyecto de transformación (1894) realizado por el Director de Obras Municipales de Santiago, Don Manuel Concha. Se basaba en la apertura de cuatro diagonales que unían la Estación Mapocho, la Estación Central, el Parque Cousiño (hoy O’Higgins) y el Cerro de Santa Lucía. Desde este último se cierra el circuito con la unión con la Estación Mapocho.

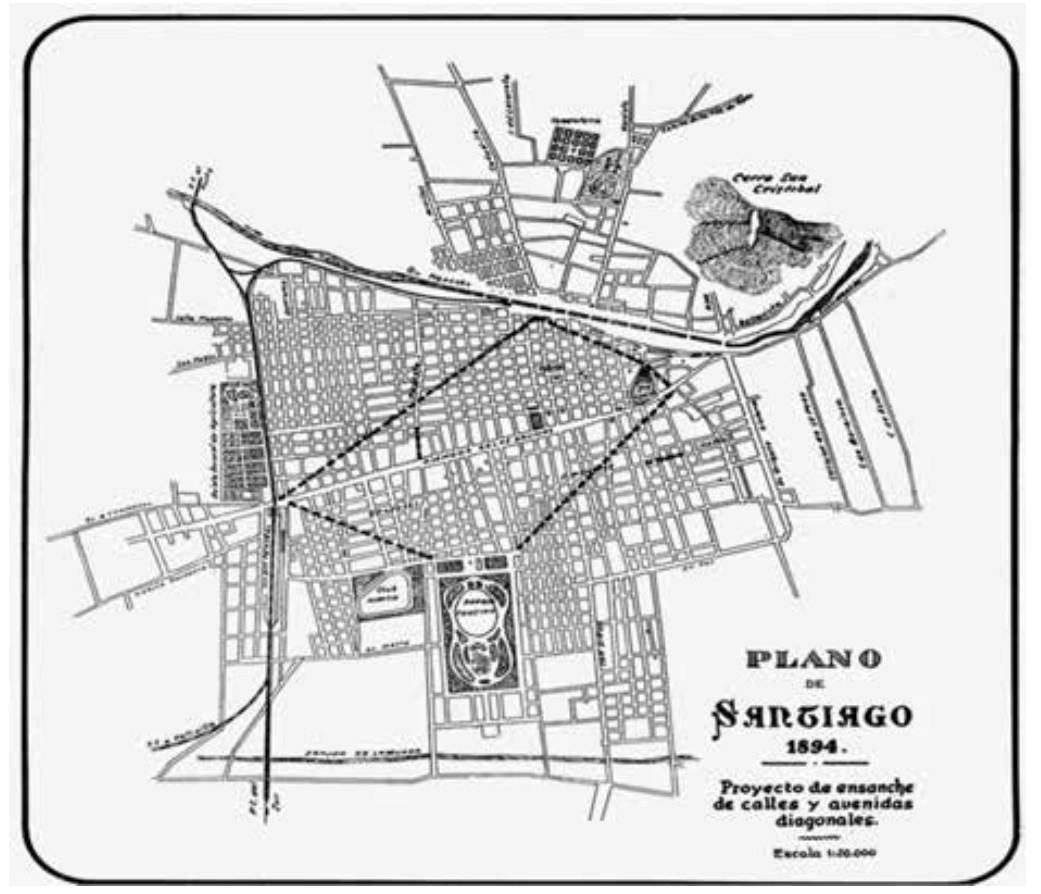

Imagen 13. Plano de Santiago Primer proyecto de transformación (1894). Contemplaba ensanche de calles y avenidas diagonales. Fuente: http://www.ucentral.cl 
Imagen 14. Plano de Santiago Plano de Santiago con el Ferrocarril de circunvalación y las avenidas diagonales. Fuente: http://www.ucentral.cl
Segundo proyecto de transformación (1912) Este nuevo proyecto, presentado a la consideración del Congreso en 1912 repite el esquema de diagonales de 1894 pero suprime el tramo Santa Lucía - Estación Mapocho. Incorpora en cambio dos nuevas diagonales desde el cerro Santa Lucía a la intersección de la Avenida Vicuña Mackenna con Irarrázabal y desde allí a la Estación San Diego.

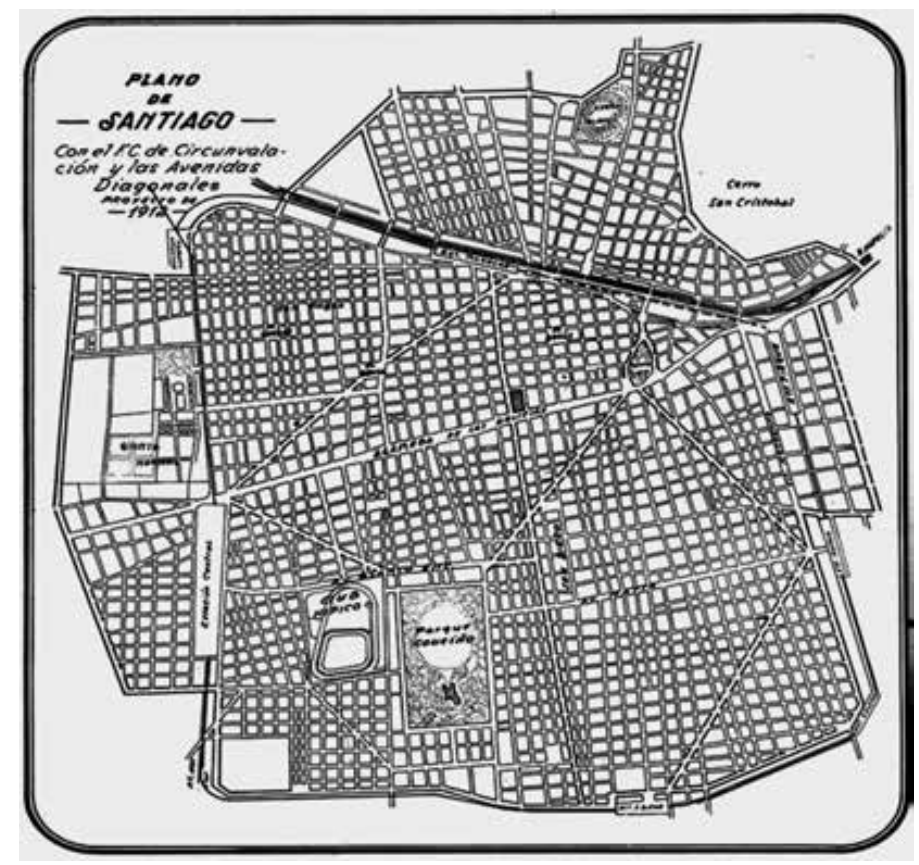

Tercer proyecto de transformación (1912) emanado poco tiempo después del segundo proyecto, contenía algunas proposiciones adicionales que incidían en el reconocimiento de barrios y en la unión de plazas existentes, mediante diagonales.
Imagen 15. Segundo proyecto de transformación (19/2) de la Sociedad Central de Arquitectos Fuente: http://www.ucentral.cl

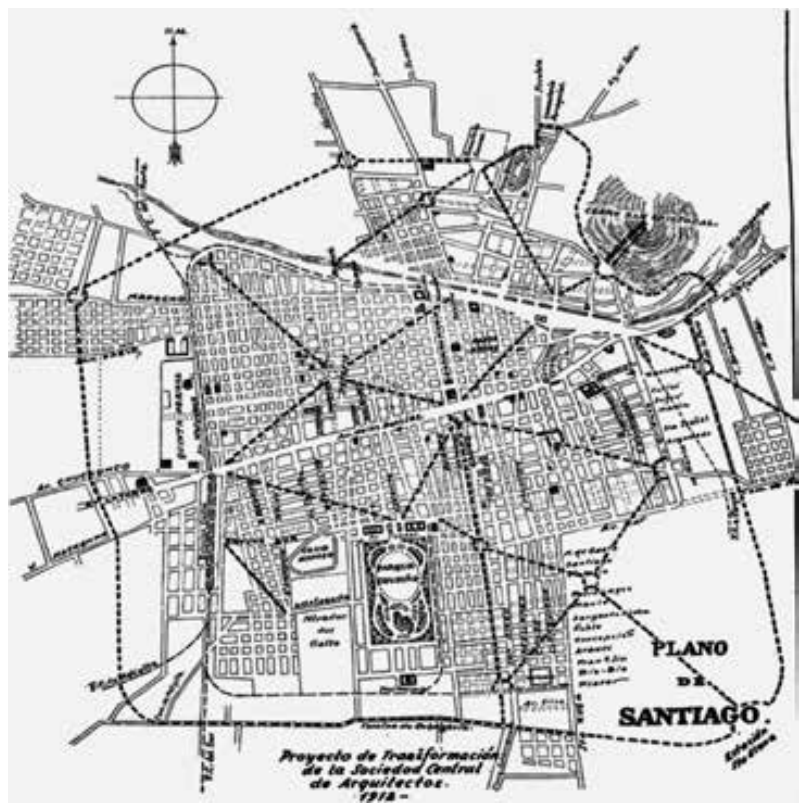


Cuarto Proyecto de transformación (19/3) Por iniciativa del Cónsul Chileno en San Francisco, se elaboró este proyecto por parte del arquitecto Coxhead. Su característica principal era la creación de una circunvalación poligonal que, sin considerar la topografía local, pasaba por sobre el San Cristóbal como si no existiese. Hacia el sur de Alameda, con el centro en el Palacio de la Moneda, se trazaría un semicírculo tangente a la Avenida 10 de Julio. Otra de sus proposiciones era extender la calle Agustinas hacia el oriente, por debajo del Cerro Santa Lucía con un túnel.

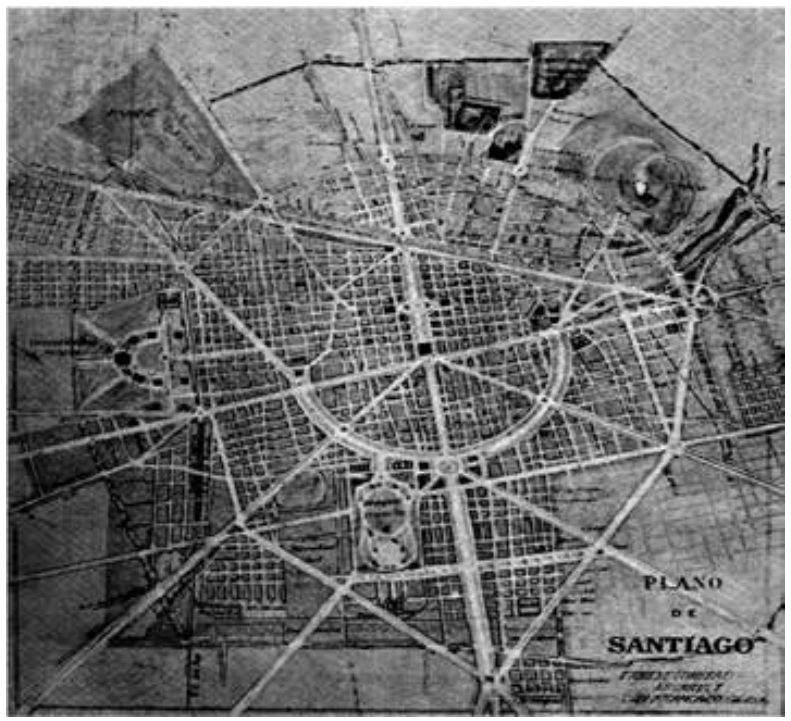

Sexto proyecto de transformación (1915). El comité de transformación de Santiago, presidido por el Intendente Don Alberto Mackenna Subercaseaux y formado por los señores Carlos Carvajal, Enrique Döll, y Emilio Jecquier presentó en 1915, una nueva propuesta que, lejos de cualquier influencia hausmanniana, se caracterizó por su sobriedad y racionalismo.

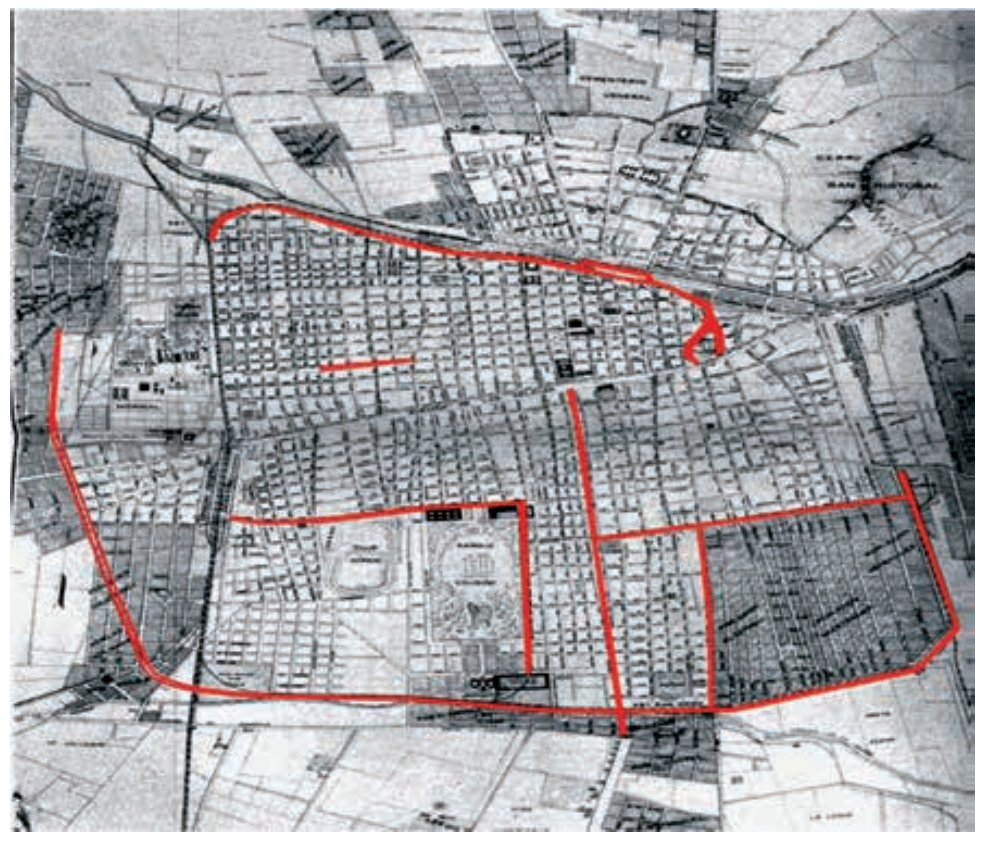

Imagen 16. Cuarto proyecto de transformación de Santiago (1913). Arq. Ernest Coxhead, San Francisco California, USA. Fuente: http:// revistaurbanismo.uchile.cl

Imagen 17. Sexto proyecto de transformación con las principales avenidas indicadas por la Comisión de Transformación. Fuente: http://www.ucentral.cl 


\section{LA FINALIZACIÓN DE UNA MODA: EL SÉPTIMO PLANO DE TRANSFORMACIÓN (1928)}

Lejos de las fantasías escenográficas, Carlos Pinto Durán publicó en 1928 un pequeño folleto titulado "Proyecto de Transformación Definitiva de Santiago" (Talleres de El Diario llustrado, Santiago, 1928). Este último proyecto deja concluir que después de Vicuña Mackena, la ciudad de Santiago tomó rumbo hacia un curioso período de 13 años, comprendidos entre 1912 y 1925, donde el gran tema de discusión pública fue la transformación de la ciudad. Los historiadores hablan de numerosos detractores, pero hasta hoy sus nombres han permanecido anónimos. Entre los defensores se cuentan, en primer lugar, el Intendente de Santiago Don Alberto Mackenna Subercaseaux y el Senador por Santiago Don Ismael Valdés Valdés. Ambos personajes escriben artículos y libros, imparten conferencias públicas e inauguran exposiciones relativas al tema de la transformación de Santiago, la gran aldea que querían convertir en "ciudad moderna". ${ }^{20}$ También es curioso anotar que aunque Vicuña, precursor de las transformaciones de Santiago, hubiese sido influenciado por el París de Haussmann, nunca llegó a plantear grandes diagonales ni ejes por tensión como lo hizo el barón. Seguramente Vicuña era consciente de que la sociedad capitalina en ningún momento habría aceptado intervenciones tan drásticas en el espacio privado y que estos proyectos a la parisina seguramente habrían endeudado una administración pública que no contaba con los fondos para tan costosa empresa.

Hoy, en el plano de Santiago aún aparecen los ejes viales de la época de Vicuña, con algunas adecuaciones que responden más a los dos últimos proyectos de transformación que en alguna manera sacan provecho de la visión innovadora pero realista del prefecto Vicuña Mackenna, sin duda uno de los más representativos personajes de la historia urbana de Santiago.

Imagen I8. Plano de Santiago Siglo XXI.Fuente: http://earth.google.com

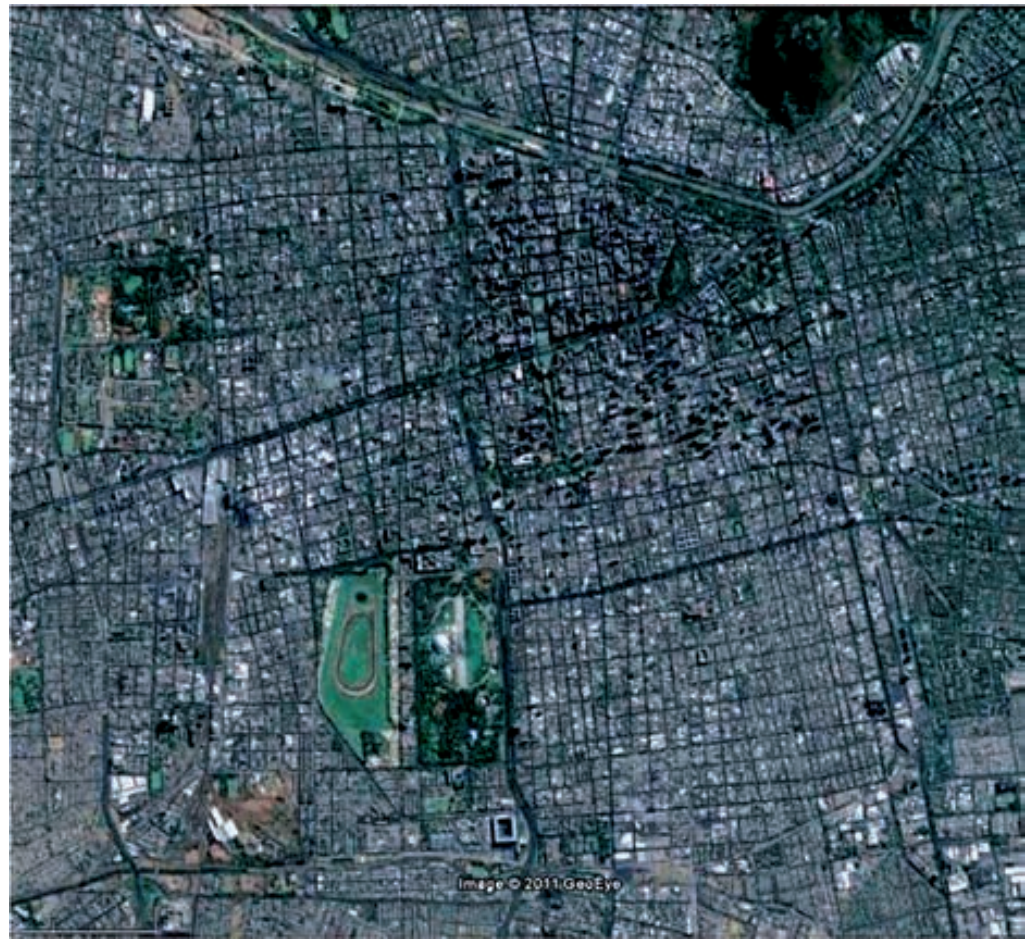

20 MACKENNA SUBERCASEAUX, Alberto. "Santiago Futuro" En MARTíneZ lemOINE, René. Santiago. Los Planos de transformación 1894-1929 


\section{BIBLIOGRAFÍA}

BENÉVOLO, Leonardo. Diseño de la ciudad. Barcelona, Gustavo Gili, 1977

Historia de la Ciudad. Bari, Ed. Laterza, 2006

Los orígenes del urbanismo moderno. Bari, Laterza, 2005

Historia de la arquitectura moderna. Barcelona, Gustavo Gili, 1977

Biografías y Vidas. Benjamín Vicuña Mackenna. Disponible en Internet en: http://www. biografiasyvidas.com/

CARS, J.; PINON, P. París Hausmann. París, I99I

DES CARS, J., PINON, P. París Hausmann. París, Éditions du Pavillon de l'Arsenal/Picard Editeur, 1991

DONOSO, Ricardo. Don Benjamín Vicuña Mackenna. Santiago, Imprenta Universitaria, I 925

FRASCINA, F., BLAKE, N., FER, B., GARB, T., HARRISON, Ch. La modernidad y lo moderno. La pintura francesa en el siglo XIX. Madrid, Akal, 1998

LE CORBUSIER. Principios de Urbanismo (La Carta de Atenas) Barcelona, Ed. Planeta, 1993

Memoria Chilena. Portal de la cultura de Chile. Disponible en Internet en: http://www. memoriachilena.cl

Municipalidad de Santiago, 450 Años y hacia el Siglo XXI. Disponible en Internet en: http:// www.municipalidaddesantiago.cl/comuna/comuna_450-adelante.php

MUNIZAGA VIGIL, Gustavo. Diseño Urbano: Teoría y Método. Santiago, Ed. Alfaomega, 2002 Las Ciudades y su Historia. Una aproximación. Santiago, Ed. Alfaomega, 2002

ORREGO VICUÑA, Eugenio. Vicuña Mackenna, vida y trabajos. Editorial Zig-Zaag, 1951

PETTI PINHEIRO, Elisa. Europa, Francia y Bahía. La difusión de los modelos europeos. Escuela técnica Superior de Arquitectura, Universidad Politécnica de Cataluña, Barcelona, 2000

MARTÍNEZ LEMOINE, René. Santiago. Los Planos de transformación I894-1929 En: Revista Electrónica DU\&P. Diseño Urbano y Paisaje, Volumen IV No. 10, Centro de Estudios Arquitectónicos, Urbanísticos y del Paisaje, Universidad Central de Chile, Santiago, 200 I

MACKENNA SUBERCASEAUX, Alberto. Santiago Futuro. Barcelona, Imprenta Barcelona, 1915.

Paris avant et après Haussmann. Disponible en Internet en: http://www.lefigaro. fr/p hp

Santiago, Chile. History. Disponible en Internet en: http://www.macalester.edu/

Transformación de París durante el Segundo Imperio. Disponible en Internet en: http:// www.esacademic.com 